\title{
RESILIÊNCIA URBANA E COMERCIAL EM ÁREAS CENTRAIS
}

\section{THE URBAN RESILIENCE IN CENTRAL RETAIL AREAS}

\author{
Dra. Susana Mara Miranda Pacheco \\ Universidade do Estado do Rio de Janeiro \\ e-mail: susanamp@infolink.com.br
}

\begin{abstract}
Resumo: Este artigo aborda as mudanças em áreas comerciais da cidade, focalizando o tema da resiliência urbana. Trata-se de uma reflexão de natureza teórico-conceitual que remete à produção do espaço urbano e à atuação de agentes sociais em áreas centrais. $\mathrm{O}$ conceito de resiliência é apresentado em suas inúmeras definições a partir de revisão de literatura. Os agentes produtores do espaço urbano em áreas centrais são identificados mediante sua participação nos processos de mudança que marcam o movimento do fenômeno urbano. $\mathrm{O}$ artigo evidencia a necessidade de política urbana voltada para a resiliência da área central das cidades.
\end{abstract}

Palavras-chave: resiliência, comércio urbano, áreas centrais, produção do espaço, agentes sociais.

Abstract: This article is about changes in retails city areas and focus upon urban resilience. The text raises the theoretical and conceptual aspects of the question, faced with the production of space and the role of actors. The resilience concept is presented in a general overview of literature. The production of space actors are identified concerning the anchor role they acquire for the urban changes. The article claims the necessary role of public authorities with resilience in city central areas.

Keywords: resilience, urban retail, central areas, production of space, social actors.

\section{Introdução}

Este artigo pretende abordar as mudanças em áreas comerciais da cidade, enfocando o tema da resiliência urbana. A problemática urbana exibe-se em diferentes dimensões (econômica, política e cultural) a serem apreendidas na produção do espaço interno da cidade. Todas elas incidem sobre as atividades comerciais, dada à relação genealógica entre cidade e comércio. Por sua vez, as escalas conceituais e cartográficas se entrelaçam, sugerindo análises que se justapõem ou sobrepõem de acordo com os interesses de investigação ou gestão do território. A globalização impõe a articulação da pequena com a grande escala, pondo em relevo o papel dos governos locais nas 
intervenções urbanas, especialmente as de caráter urbanístico, como os projetos de requalificação de áreas centrais.

As cidades respondem às imposições do movimento global do capitalismo em sua faceta econômica mais inclemente, provocando polarizações que se repetem em diversos âmbitos do desenvolvimento urbano, atualizando a contraposição entre atividades/grupos empresariais de grande porte e as atividades econômicas que circunscrevem o que Santos (2005) denominou de circuito inferior da economia urbana ou, em um contexto diferenciado de polarização, as pequenas firmas tradicionais de comércio varejista. No curso do processo de concentração de capital e de distribuição (SALGUEIRO, 1996), transforma-se o comércio em suas formas de organização e logística, mudando de status o consumo urbano.

Neste contexto de mudanças e crises na realidade urbana (LEFEBVRE, 1976) se insere o tema da resiliência, em destaque neste artigo. $\mathrm{O}$ objeto de estudo refere-se ao comércio varejista tradicional de rua, em sua conexão com o conceito de resiliência, dada a condição de mudança supramencionada, que remete à atualidade (acúmulo de crises/mudanças). Trata-se de uma etapa do processo urbano, na qual o centro sofre os efeitos da descentralização e transbordamento para outras partes da cidade, remetendo a outras concentrações do setor terciário da economia urbana, tal como aconteceu no tecido urbano do século passado, particularmente em metrópoles. A centralidade ganha destaque na medida em que o fenômeno urbano na atualidade se pauta pela condição de concentração em cidades que passaram pelos efeitos do capitalismo industrial, que ressaltou a disseminação das trocas e o consumo de mercadorias. Portanto, as mudanças em áreas de reconhecida centralidade (área central) serão aqui evidenciadas, por ser o centro comercial, repleto de objetos e símbolos, fundamental para a dinâmica capitalista.

Sendo assim, o recorte espacial corresponde a áreas terciárias consolidadas na cidade, que ora sucumbem aos imperativos empresariais ora reagem às dificuldades de adaptação às condições hegemônicas capitalistas. Exemplos do Rio de Janeiro aparecem sem parcimônia, por razões da experiência de pesquisa da autora. Porém, o caráter metodológico será preservado, com ênfase na discussão do campo teórico-conceitual, 
dando sentido à realidade que percebemos e vivenciamos e que, muitas vezes, é concebida pelo governo de modo ilógico perante nossas experiências de citadinos, isto é, ao invés de criar possibilidades de recuperação da centralidade mediante políticas de resiliência urbana, envolvendo o protagonismo notório das ruas comerciais. Para refletir sobre esta problemática urbana vamos iniciar pelo conceito de resiliência; em seguida a produção do espaço e os agentes sociais ganham força na reflexão, dada a sua possibilidade de atuação em processos de resiliência urbana.

\section{$O$ conceito de resiliência}

De início podemos distinguir o conceito-chave e sua relação com o campo conceitual consagrado pelos estudos de geografia urbana. A relação entre os conceitos é condizente com as relações escalares estabelecidas para a compreensão do objeto de estudo, isto é, se imbricam sem caráter hierárquico. O conceito de "resiliência" é essencial para entender os processos de transformação em curso na área central das cidades e a produção do espaço pelos agentes sociais. A esse respeito, PINTAUDI (2009, p. 56) aponta "a necessidade de rearticular conceitos e a pesquisar outras áreas do conhecimento que possam nos auxiliar na compreensão dos espaços de reprodução da vida, que são os lugares de materialização da realidade social."

Apesar de dinâmico e atrativo, a ideia de centro da cidade está abalada em sua imagem pelas fragilidades que o caracterizaram no último quartel do século XX. Esta foi uma tendência que se repetiu em diversas cidades do mundo. A experiência de popularização da área comercial ou a insuficiência e inadequação do planejamento do comércio urbano repercutem na dimensão de sua centralidade, minimizando-a. Sem dúvida, faltam ações políticas, econômicas e sociais para superar crises do espaço central e promover a reabilitação de zonas sujeitas a insolvências. Pensa-se, como meios de gestão urbana, no efeito Bilbao (GASNIER et al., 2011): explora-se este ideário na transformação de áreas portuárias contíguas ao centro histórico da cidade, visando integrá-la à rede de cidades ativas nos fluxos da globalização - mediante planejamento estratégico e empreendedorismo (HARVEY, 2005). No plano econômico, o comércio de médio e pequeno porte é estimulado a permanecer operativo, e o espaço da moradia

Geo UERJ - Ano 14, nº. 23, v. 2, $2^{\circ}$ semestre de 2012 p. 459-478

ISSN: 1415-7543 E-ISSN: 1981-9021

http://www.e-publicacoes.uerj.br/index.php/geouerj 
recebe investimentos que implicam em mudanças de prestígio da zona, com tendências a gentrification.

Decerto, recuperar o centro significa requalificar o espaço comercial; mas, em face da tendência à descontinuidade (econômica e espacial) da atividade comercial na área central (CORRÊA, 1989; DUARTE, 1967), identificando-se zonas de fraca densidade comercial herdadas de intervenções urbanas precedentes - como no caso do Plano Agache no Rio de Janeiro - a circulação de pessoas constitui um elemento relevante de qualquer plano, programa ou ação política de governo, não devendo ser menosprezada. Em outras palavras, as experiências recentes de revitalização de áreas centrais ilustram que operações de requalificação comercial e recreativa exigem interação espacial, o que remete à tradição de passantes pela rua comercial no antigo centro histórico e em áreas centrais (CBDs) da cidade industrial.

Em face de conjunturas que envolvem a ordem distante (LEFEBVRE, 1976) e as relações que configuram o local, no cotidiano de práticas e ações de agentes produtores do espaço, o tema da resiliência da área central e, especificamente, do espaço comercial tradicional, torna-se oportuno para as análises críticas do espaço urbano. Existe resiliência em áreas centrais com o ressurgimento de atividades antes vigorosas como funções centrais. A resiliência pode assumir aspectos e intensidade diferentes. Mas é um sintoma próprio de situações de crises e impasses conjunturais que necessitam superações, em outras palavras, políticas de resiliência que considerem a relação entre os lugares da cidade (GASNIER et al., 2011). O caso do Rio de Janeiro merece estudo e compreensão do processo, qualificando-o.

O estudo da resiliência envolve relações entre área comercial e a cidade, portanto interações espaciais (CORRÊA, 1997) em diferentes períodos de altos e baixos na evolução urbana, sugerindo que a análise abranja um período longo, no qual a dimensão política influi diretamente; no caso do Rio de Janeiro, vale dizer, desde meados do século XX, com a mudança da capital federal. Os planos referentes à cidade exigem uma análise que considere o tempo, pois muitos não se materializam ou concluem, e outros correspondem a operações recentes (GASNIER et al., 2011). Este autor nos alerta, ainda, sobre o descompasso entre redesenvolvimento social do lugar e 
seu redesenvolvimento material (GASNIER et al., 2011, p. 72-3). Sendo assim, as obras urbanas podem acontecer sem uso imediato ou pleno, o que nos explicaria em parte as dificuldades econômicas e o relativo aproveitamento cultural de equipamentos do Corredor Cultural, por exemplo, no centro do Rio de Janeiro. Por sua vez, em cidades europeias o descompasso entre projeto e apropriação do espaço pela função social está se revelando nas recentes reconversões urbanísticas e obras monumentais como $22 @$ bcn e Forum de las Culturas, em Barcelona, e a monumental Ciudad de las Artes y la Cultura, em Valencia, cujo uso não está atendendo às expectativas ${ }^{1}$; porém, a vitalidade de ruas comerciais europeias tende a minimizar as inflexões e contradições do tempo-espaço. Portanto, cabe discorrer sobre o conceito como um processo e sua aplicação à área de estudo, ainda que o alvo seja a evolução recente.

Resiliência de lugares centrais pressupõe conexão sincrônica entre atores envolvidos em processos de requalificação/revitalização/reapropriação em diversas partes da cidade, impedindo o efeito de opacidade de áreas antigas ao respeitar a complementaridade (funcionalidade) e a diversidade (sociabilidade) desejadas para a cidade, em sua combinação de diferenças desejáveis (GASNIER et al., 2011; JACOBS, 2000) e respeitando as centralidades de antes. Portanto, é um processo que se materializa na interseção de diversas ações em diferentes escalas. $\mathrm{Na}$ área comercial implica exatamente diversidade de preços, consumidores e de horas de funcionamento (GASNIER et al., 2011), constituindo um sistema comercial (GUIMARÃES et al., 2011).

Segundo Kärrholm et al. (2011), o conceito de resiliência tem uma abordagem que abrange princípios físicos relativos à velocidade do retorno à normalidade e manutenção de eficiência de objetos. A abordagem ecológica também remete ao tempo de resistência a situações externas sem perdas no modo de funcionamento. Para os ecologistas o conceito de resiliência altera o (antigo) conceito de sustentabilidade. Envolve volatilidade, flexibilidade e descentralização. Na perspectiva da resiliência, a mudança pode criar novidade, oportunidade de desenvolvimento e inovação (MONTENEGRO, 2010). Quando abordada a questão climática, uma pergunta-chave se impõe, qual seja: Quantos impactos o sistema pode receber até se tornar outra coisa totalmente diferente? Aqui parece germinar a essência da resiliência, a autora chama a 
atenção, e seguindo o raciocínio, extrapolando o circuito dos ecologistas, a cidade seria a quintessência do complexo sistema de adaptações - complex adaptive system (MONTENEGRO, 2010). Sendo assim, pode ser um lugar para explorar a resiliência. Obra do homem, a cidade pode ser explicada pelo comportamento humano, sendo este um território ainda pouco explorado. Nesta fronteira pode estar o geógrafo interessado na cidade como lugar de moradia, trabalho e consumo, juntamente com economistas, cientistas políticos, cientistas sociais que estudam o funcionamento do habitat/habitar e a absorção de impactos. Nesta perspectiva, New Orleans após o Katrina tem sido um interessante caso para o estudo científico da resiliência.

A perspectiva humana da resiliência pode ser definida como a capacidade humana de ajustar-se, resistir e se recuperar das adversidades (ROJAS, 2011). Ou, simplesmente, segundo este autor, ter aptidão para lidar com os avatares do dia a dia. Portanto, as análises não devem estar focadas nas fragilidades, e sim na capacidade de sobreviver. Existe a crítica sobre o declínio do espaço público, mas, lamentavelmente, não existem muitas soluções para reverter o problema. Como gestionar as mudanças em curso no mundo contemporâneo? Como introduzir mudanças na economia e na estrutura social? Estas são perguntas a exigir novas abordagens teóricas, assim como mudanças no campo político e nas atuações territoriais (CAPEL, 2011). Esta pauta alude a novos modelos organizativos para os centros da cidade (e seu espaço comercial); pensar em resiliência, portanto, constitui uma linha de reflexão sobre as atuais condições urbanas em metrópoles como o Rio de Janeiro, Lisboa e Napoli, entre outras.

Conforme SALGUEIRO (2011, p. 26), resiliência refere-se ao processo de adaptação a situações que mudam constantemente. Pensando nos conceitos de território e região, à luz dos argumentos da autora, fica claro que não se trata de medir a resiliência de uma cidade ou região, como as teorias neoclássicas propunham ao verificar equilíbrio preexistente às crises. Melhor seria verificar a adaptação à competitividade, a mudanças tecnológicas e pressões do mercado (SALGUEIRO, 2011), na medida em que processos políticos e econômicos estão no cerne da resiliência. Resiliência é um discurso atual, muitas vezes acompanhado da sustentabilidade. Mas acreditamos que suplanta esse limite quando articulado à produção do espaço urbano, com ênfase nas ações dos agentes sociais.

Geo UERJ - Ano 14, no. 23, v. 2, $2^{\circ}$ semestre de 2012 p. 459-478

ISSN: 1415-7543 E-ISSN: 1981-9021

http://www.e-publicacoes.uerj.br/index.php/geouerj 
O estudo da resiliência (adaptação) condiz com o estudo de áreas comerciais. Implica mudança, adaptação e melhoria do comércio; manutenção de status, admitindo novos formatos, até mesmo os shoppings verticais ou shoppings centers e diferentes ramos de atividade (PACHECO, 2011; GUIMARÃES et al., 2011). O comércio varejista é uma atividade humana antiga: ora é inovadora, ora fica inerte e declina, necessitando reação e adaptação. (SALGUEIRO, 2011).

No dizer de RIPOL (2000) o comércio contribui para a configuração territorial das cidades e para o fortalecimento do tecido social, animando a vida humana. É elemento de turismo, o que nos remete à retomada do centro histórico do Rio de Janeiro e a chegada de navios de cruzeiro; sói ser usual ver a Confeitaria Colombo repleta de turistas brasileiros e estrangeiros fotografando o recinto deslumbrante e degustando os produtos oferecidos. O autor chama a atenção para a função social do comércio, a começar pelo abastecimento. Os cidadãos compram e consomem bens e serviços. No ato da compra se encerram experiências e atitudes que expressam relações sociais. Sendo assim, podemos analisar o comércio pela perspectiva do comportamento humano, no caso do comércio em área central, citadino. De fato, implica modos de vida, uma cultura urbana que marca as cidades de hoje; é um suporte fundamental para a vida urbana do centro da cidade, combinando com as funções diretivas a partir de instituições públicas e privadas, negócios entre firmas, considerando que comércio implica atividades de distribuição e consumo. (RIPOL, 2000).

Retomando a abordagem do conceito de resiliência, segundo Salgueiro (2011, p.40) "resiliência expressa-se na habilidade de enfrentar situações críticas por meio de ações que tendem a recolocar a funcionalidade de serviços individuais ou uma área comercial." Relevante na aplicação do conceito seria considerar a dinâmica de um sistema comercial, (como o de uma área central), sua mudança constante; a evolução do lugar; e que o planejamento e a atuação de atores pode favorecer a resiliência ao nível local (SALGUEIRO, 2011, p. 30). O conceito de resiliência revela-se oportuno e passível de aplicação em situações cujo sucesso depende de atuações individuais e associativas para mudar as circunstâncias com habilidade. Pode-se planejar a mudança no sistema comercial, assim como se planejam transformações na cidade. A autora 
lembra que permanência e mudança correspondem ao processo urbano e o que acontece no sistema varejista ilustra essa condição da cidade.

Ainda sobre a resiliência de um sistema de comércio urbano, podemos incluir a definição de Kärrholm et al. (2011, p. 46): habilidade de diferentes tipos de comércio varejista, em diferentes escalas, para adaptar-se a mudanças, crises ou impactos mudando o sistema de equilíbrio, sem perder a performance de suas funções de uma maneira sustentável. Acontece que não necessariamente o grande comércio sobrevive às mudanças impostas pelo tempo; por outro lado, o pequeno pode se adaptar e se manter ativo. Algumas firmas comerciais funcionam como titãs, num contexto em que fortuitamente podem contar com uma conjuntura favorável (ROJAS, 2011). Mas a experiência trazida pela literatura e casos empíricos reforça o aspecto de que para superar crises, as firmas devem contar com o apoio, cooperação ou tutela de entidades que funcionam como salva-vidas ou para raios. (ROJAS, 2011).

Do processo de resilência participam diversos atores, desde os comerciantes aos consumidores, passando pelos investidores e a administração pública da cidade. Seu entendimento pressupõe o planejamento do sistema varejista da cidade para fazer face às mudanças, encontrando respostas e adaptando-se sobremaneira ao consumidor, ampliando seu leque de escolhas (SALGUEIRO, 2011, p. 35). Em síntese, isso implica no sucesso ou fracasso do comércio varejista. Em outras palavras, a circunstância de que marginalidade e insegurança do espaço público denotam fragilidade, ao passo que concentração e diversificação de oferta de bens e serviços, assim como amenidades (oferta de lazer cultural para turistas), lojas âncoras, alta densidade de ocupação do espaço, ausência de vazios intersticiais e acessibilidade favorecem a dinâmica exitosa da área central da cidade.

O debate atual em torno do espaço comercial como elemento fundamental à própria existência da centralidade nas cidades admite pensar em resiliência no sentido lato do termo, mais além de resistência e sim em termos de capacidade de adaptar e produzir em contextos de mudanças ou impactos diretos na economia urbana, na imagem da cidade e no comportamento dos cidadãos.

Geo UERJ - Ano 14, nº 23 , v. 2, $2^{\circ}$ semestre de 2012 p. $459-478$

ISSN: 1415-7543 E-ISSN: 1981-9021

http://www.e-publicacoes.uerj.br/index.php/geouerj 
As problemáticas do comércio e do consumo, em sua relação com o desenvolvimento social, revelam a identificação entre o novo e o velho. Os centros podem combinar diversos tempos sociais expressos nas formas comerciais. Temos comércio varejista tradicional e obsoleto, mas também muitos comércios que se renovam e outros que se instalam em condições de modernização. Milton Santos (1994, p. 98) nos ensinou que muitos elementos entram em jogo na organização espacial: a política, a economia, a sociedade e a cultura. Pensando na área central, o novo tende a polarizar o velho na estrutura comercial. As atualizações não se dão simultaneamente, em virtude das defasagens (SANTOS, 1994a, p. 99). Em outros termos, a novidade quando chega a um lugar pode causar impacto. O Rio Scenarium, casa noturna na rua do Lavradio, no Rio de Janeiro, muda a imagem do centro da cidade no seu limite externo. Invade o lugar com a nova função de entretenimento, incluindo o turismo. Contribui para projetar a valorização do solo para um eixo antes desvalorizado, nas imediações, revelando que a situação da área central está em processo: o urbano em movimento na estrutura da área central consolidada pelo tempo como concentradora de atividades gestoras ou funções centrais. Mas a própria área tem sua periferia diversificada, na qual as variáveis velhas se mantêm em resistência. A paisagem urbana é reveladora neste sentido. O velho faz parte de um contexto cujo funcionamento permite a resistência a partir de uma combinação de condições existentes, no contexto das novas tecnologias, dos sistemas logísticos e de gestão, e das inovações introduzidas nas atividades distributivas.

São muitas as variáveis que influem na cidade e em sua área central: locais e externas, novas ou velhas. Os comércios tradicionais e os de hoje têm a ver com a divisão do trabalho de antes e a de hoje. (SANTOS, 1994b). As novas divisões do trabalho redistribuem funções sobre o território. Ao fazê-lo, processualmente, transformam o lugar, na medida em que recombinam elementos e rearranjam o espaço (SANTOS, 1994b, p.125). No centro do Rio de Janeiro existem parcelas do espaço construído que constituem o que foi herdado do tempo pretérito e que se encontram muitas vezes submetidas a processos de inércia dinâmica, representando o local, a extensão do centro na zona portuária, por exemplo, ao passo que o novo, ou seja, os elementos de transformação, dizem respeito a uma ordem distante, já que consistem em 
uma divisão do trabalho que extrapola a ordem local (SANTOS, 1994b, p.126). Sabemos que o espaço urbano vai sendo modelado por decisões de atores politicamente hegemônicos, sobremaneira o Estado, que estabelece os usos do solo, cria zonas especiais, faz intervenções das atividades humanas implicando em mudanças significativas para o conjunto da cidade. Abordaremos a seguir essas atuações e processos.

\section{A produção do espaço varejista na área central e os agentes sociais envolvidos}

O conceito de resiliência urbana é aplicado à escala local, na qual o fenômeno ganha força. Sua abordagem analítica requer o foco nas relações entre agentes sociais da produção do espaço comercial, cuja espacialidade implica em ações acumuladas do passado e propósitos que dirigem a trajetória do processo atual. Isto possibilita a legibilidade do fenômeno urbano em questão. Vamos centrar esta parte do artigo na produção do espaço e na atuação dos agentes sociais envolvidos na questão da resiliência urbana, sem privilegiar, nesta oportunidade, o papel do consumidor. Neste escopo se delineiam os passos metodológicos para compreender e qualificar o estágio de desenvolvimento das forças representativas da atividade comercial varejista, sua expressão espacial e repercussões sobre o destino cambiante do centro das cidades.

De início, precisamos contextualizar o tema da resiliência em sua relação com a cidade e a produção do espaço urbano. Incide nesta relação o já mencionado comportamento social de agentes modeladores do espaço, que é sumamente produção social. Vale insistir que a relação entre os agentes que atuam em processos de resiliência de áreas centrais, se fundamenta em parcerias entre planejadores, comerciantes e consumidores, no intuito de romper as barreiras das dificuldades motivadas pelas mudanças na sociedade urbana, minimizando negatividades e maximizando as condições ótimas de recuperação do ambiente comercial urbano. Resiliência consiste na decisão de planejadores e técnicos de trabalhar em parceria com consumidores/usuários, na superação de vulnerabilidades: avaliar a dinâmica das mudanças, minimizar as negatividades e desenvolver resiliência em áreas comerciais, diversificando bens e serviços. Sem dúvida, a resiliência tem um papel no planejamento urbano que não deve 
ser menosprezado como elemento de análise da matriz de relações, tendo a própria cidade como resiliente. A cidade é constituída de tempo rápido (shopping centers) e tempo lento (comércio tradicional), que não deve ficar em inércia diante das mudanças, senão pode desaparecer do sistema comercial (CACHINHO, 2010).

A área comercial é uma expressão concreta das ações empreendidas pelos agentes produtores do espaço urbano. Portanto, não devemos dissociar o tema da resiliência de áreas comerciais do papel desses agentes, contemplando os comerciantes, os consumidores, o Estado, as instituições de classe e os empreendedores imobiliários. As formas que a eles correspondem são marcadas pelos significados que lhes são impressas. Nelas estão a cultura urbana e as práticas sociais de reprodução da sociedade e do espaço. Mas o foco central pode estar no comerciante e sua capacidade de adaptarse às mudanças impostas pelo modelo de desenvolvimento econômico.

Os produtores do espaço urbano, portanto, atuando na escala geográfica da área central, configuram o espaço de consumo, ou seja, o espaço comercial varejista com suas formas diversas e conteúdos. Apesar do reconhecimento das relações estabelecidas na escala de abrangência do processo, é a escala da cidade que está em jogo, com as especificidades das espacialidades-temporalidades, marcadas pelas relações institucionais e a administração pública, elementos constitutivos da posição política da cidade, conquistada séculos antes. Mas as produções do passado se acumulam e combinam com o presente stricto sensu, destituído de forças pretéritas. Os atributos do espaço são reavaliados no presente em transição, requerendo uma economia política da cidade que mantenha sua posição na organização do território e a vida urbana que servia de modelo à sociedade urbana. No que se refere à economia política, Capel (2011) alude à nova tecnologia do poder, surgida no século XVIII e apontada por Michel Foucault nos anos de 1970: controlar as populações e o território, o que conduziu o poder ao “governo econômico" e à gestão do "problema político da população", originando a economia política. Segundo Capel (2011), os liberais mantiveram essa tradição ao governar, o que podemos assistir na atualidade. A atuação do Estado pode variar temporalmente e de acordo com as tendências político-partidárias e alianças manifestas na cidade e nas relações de sua administração pública nos termos da gestão urbana. Pode ser uma gestão filosoficamente arraigada na compreensão socialista ou neoliberal 
dos processos em curso na estrutura social, com repercussões diretas na apropriação e uso do solo urbano.

Entender o papel do Estado (com ênfase na governança, envolvendo comunidade e organizações sociais, parcerias público-privadas), portanto, pode ser fundamental para entender a questão da resiliência na cidade em sua dimensão econômica, política e cultural. Nem sempre temos uma política diretamente voltada para o setor varejista, além da regulamentação das atividades, das licenças de uso e do zoneamento urbano. As estratégicas mais recentes na esfera do planejamento procuram a conexão das áreas comerciais, estabelecendo a circulação no território; porém, campanhas para atrair consumidores costumam levar à polarização de diferentes tipos de áreas comerciais ao invés de interrelação e diversidade balanceada.

O Estado tem uma participação importante na produção do espaço, favorecendo a resiliência de áreas comerciais. Os limites da produção e os parâmetros de uso do espaço interno da cidade são estabelecidos pelo Estado, na instância do poder jurídico e legislativo, mediante a elaboração, promulgação e regulamentação de leis, sem as quais as práticas espaciais de diversa natureza perderiam legitimidade para a apropriação e uso pelas atividades humanas. No conjunto de atribuições do Estado (normatizar, regular, elaborar planos, projetos) encontra-se o apoio a iniciativas privadas no circuito das firmas comerciais varejistas, diante de crises que se instalam afetando o processo de desenvolvimento econômico de áreas urbanas. As políticas públicas podem servir diretamente à reprodução de um espaço a ser renovado, como também podem ganhar expressividade nos termos atuais das parcerias estabelecidas. A garantia dos investimentos em áreas degradadas continua sendo um risco assumido muitas vezes pela administração local, que promove ações conjuntas com agentes privados (comerciantes) para salvaguardar a área de sua insolvência física e econômica. Hoje observamos uma necessidade de recentralização das atividades prestigiosas no centro tradicional cuja memória urbana é a de funções centrais. No Rio de Janeiro, a propósito, o crescimento urbano descentralizou e criou muitos subcentros, derivando a estrutura urbana de formato policêntrico.

Geo UERJ - Ano 14, nº 23 , v. 2, $2^{\circ}$ semestre de 2012 p. $459-478$

ISSN: 1415-7543 E-ISSN: 1981-9021

http://www.e-publicacoes.uerj.br/index.php/geouerj 
Os comerciantes estão na história urbana da cidade como protagonistas desde primórdios da organização do espaço. O capital mercantil sempre esteve no cerne do desenvolvimento urbano e até hoje os comerciantes atuam juntamente com as prefeituras em políticas urbanas, na lógica do planejamento estratégico, sem falar na função das atividades terciárias na produção, circulação e consumo, processos explicativos dessa aglomeração que chamamos cidade. A morfologia urbana do espaço intraurbano, por sua vez, é devedora das ações humanas combinadas ou conflituosas, frutos de ideários sobre o modo de se aglomerar em cidades, de construir a paisagem urbana e administrar visando seu funcionamento e aspectos relacionais. A morfologia das áreas centrais exprime a importância das trocas comerciais mediante os fixos existentes há longa data nas cidades, ou seja, as lojas, escritórios, ruas comerciais etc.

Segundo Corrêa (2011, p.46), o Estado também controla a valorização do solo diferenciando zonas, e estipula impostos pela propriedade e uso do solo, o que explicaria, a nosso ver, as diferentes zonas de uma área central e os valores diferenciados no mercado imobiliário. $\mathrm{O}$ autor nos fundamenta sobre o papel do Estado, fato que verificamos na dotação de bens urbanísticos e infraestruturas, engenharias e reengenharias que notabilizaram as gestões dos governantes e administradores da cidade, definindo o ambiente físico construído e a morfologia urbana; nela o sítio constitui um elemento definidor de processos espaciais que implicaram na divisão social e econômica do espaço urbano. Quero crer que a centralidade é segmentada, na medida em que não coincidem no território as práticas socioespaciais de grupos sociais diferenciados em termos de poder aquisitivo (SPOSITO, 2011, p.140). Podemos pensar na centralidade do espaço comercial tradicional e seus circuitos de consumo diferenciado.

De fato, é sabido que as firmas do setor terciário da economia urbana desempenham um papel ativo na produção do espaço. Cabe perguntar, porém, se os pequenos empresários do setor varejista têm capacidade produtiva para manter e recuperar a histórica referência da área central, revelando potencialidades no desenvolvimento econômico e cultural que identifica os centros de metrópoles. Convém mencionar, ainda, o comércio informal e ambulante que "apropriam" o espaço fora da tradição capitalista de apropriação fundiária e da propriedade privada. A ocupação pode 
ser esporádica, transitória no espaço físico das ruas comerciais ou reguladas estas atividades ditas informais em áreas estabelecidas como os camelódromos do centro do Rio de Janeiro, produzido como solução para neutralizar conflitos entre agentes sociais. Hoje o status de informalidade parece pouco condizente com sua presença marcante, tanto no ambiente construído como na esfera do consumo, fortalecendo-se as relações existentes no circuito inferior da economia urbana hoje muito modificado (SANTOS, 2004).

Os comerciantes assumem papel de destaque na política de resiliência, em sua conexão com a produção do espaço, configurando a área central mediante operações, às quais se juntam os empreendedores imobiliários, revalorizando zonas e pautando a resiliência na área (SALGUEIRO, 2011, p. 42). Se pensarmos nas práticas espaciais próprias dos comerciantes varejistas vemos que estes agentes produzem o espaço em consonância com o tempo social em que vivem, no contexto (temporalidade) de uma formação econômica e social, às quais correspondem espacialidades (práticas espaciais) marcadas por fragilidades e potencialidades do processo de urbanização nas cidades, na segunda metade do século XX. Processo que interage com a área central, enquanto movimento e transformação do espaço interno da cidade. Aqui se insere a questão da resiliência, em sua conexão mais complexa e reveladora dos processos sócio-espaciais. Cabe referir, neste aspecto, a reprodução do espaço como mercadoria, produzindo contradições entre valor de troca e valor de uso, com novos atores e novos conteúdos da urbanização que articula mundo e lugar, em condições de homogeneidade e fragmentação (CARLOS, 2011).

A resiliência, portanto, é uma possibilidade vislumbrada para a urbanização de áreas centrais das cidades contemporâneas, uma vez delimitado o processo de mudanças desencadeado pela globalização. Se a temporalidade a que nos referimos implica em transformações na forma de produzir, conceber, intervir, perceber, usar, dar vida e sentido ao espaço central polarizado pelas firmas modernizadas no âmbito dos serviços e da distribuição, desvelando o caso do comércio lojista tradicional de rua, a análise deve se inscrever, sem dúvida, no contexto da relação entre a cidade e as atividades terciárias. 


\section{Considerações finais}

A questão da resiliência urbana tem uma raiz que a fundamenta na capacidade de produzir e reproduzir em condições processuais de mudanças no ritmo da urbanização e nos modos de vida urbano. Remete a processos de permanência e transformação, implicando em inércia, cristalização e renovação urbana. Recriação de configurações espaciais, para usar a expressão de Corrêa (2012, p. 44). Por certo, as formas comerciais encerram estes processos em seu conteúdo. Mais que isso: exprimem a sociedade, seus anseios de participação na vida urbana mediante o consumo, assim como suas necessidades de sobrevivência inerentes à condição humana. A reprodução social realiza-se mediante a produção e reprodução do espaço, o que nos leva a pensar na relação dialética sociedade/espaço e a mediações entre eles (CARLOS, 2011, p. 53).

Por fim, à luz do conhecimento adquirido nas pesquisas já efetuadas e pela literatura sobre o assunto, acreditamos que a resiliência é um problema simultaneamente teórico e empírico (CORRÊA, 2011). Assim é que, cabe buscar a compreensão da área comercial do centro das cidades como espaço relacional: resultado de como é percebido, concebido e vivido por diferentes agentes sociais e suas práticas que dão sentido às formas urbanas produzidas e atualizadas em face dos novos processos que as atrelam ao sistema capitalista em sua fase global, com seus imperativos sobre a produção do espaço. Mas está em foco o comportamento humano de um agente em particular, o comerciante tradicional, diante de condições adversas que o tornam frágil e perdedor no jogo de natureza econômica que marca a essência de sua atividade. Aquele que mediante sua atividade comercial cunha na cidade uma espacialidade que a marca e especifica na divisão social e territorial do trabalho. Cabe, neste contexto, o enfoque da resiliência, que implica formas de gestionar problemáticas que reverberam no desenvolvimento de negócios e no dinamismo/prosperidade de áreas comerciais tradicionais, diante de um fenômeno que desvirtua a força da cidade e motiva ações múltiplas de reconversão, em um período marcadamente urbano da organização social e dos territórios.

Geo UERJ - Ano 14, no. 23, v. 2, $2^{\circ}$ semestre de 2012 p. 459-478

ISSN: 1415-7543 E-ISSN: 1981-9021

http://www.e-publicacoes.uerj.br/index.php/geouerj 
No âmbito da produção do espaço, a análise da realidade deve "avançar" do entendimento do mundo das mercadorias e do consumo que imbrica necessidades e desejos. A análise abrange a dupla determinação da produção (CARLOS, 2011, p. 54). Contemplar a objetividade do mundo das mercadorias, ao qual se soma a subjetividade dos desejos pertinentes ao consumo das mercadorias, fundado no que elas representam para o indivíduo. Uma nova complexidade do mundo de relações sociais ilumina novas possibilidades analíticas no campo da produção do espaço urbano e comercial, mediante a resistência à lógica do planejamento que não contempla a diversidade da sociedade urbana em sua intrínseca dimensão espacial e transformadora.

\section{Nota}

${ }^{1}$ O distrito da inovação "22@ bcn” foi concebido após os Jogos Olímpicos. O projeto transformou uma antiga área industrial de Barcelona (em Poblenou), no contexto de uma ampla renovação urbana na frente marítima, objetivando implantar atividades econômicas inovadoras baseadas em novas tecnologias e ciência. O próprio nome do projeto indica esta relação; com grandes infraestruturas e intervenções, procurou-se atender a estratégia de conversão da cidade em um centro de serviços e de alta tecnologia (CAPEL, 2005). Na verdade se trata de mudança de uso do solo, o que causou repercussões no espaço da habitação, passíveis de críticas, sem alcançar o pretendido em termos de espaço produtivo, mediante atração de empresas inovadoras. Houve grandes benefícios, sim, para empreendedores imobiliários que promoveram a requalificação dos usos residencial e terciário (CAPEL, 2005). O distrito se estende até as obras monumentais construídas para o Forum de las Culturas, em 2004, que incluíram uma depuradora de águas residuais na foz do rio Besós e um palácio de exposições e sua esplanada, realizadas com financiamento público. É a respeito dessas instalações monumentais e a tendência atual de alcance reduzido do seu uso público e cultural que tecemos os comentários. Por sua vez, a Ciudad de las Artes y la Ciencia, em Valencia (ES) traz a marca da arquitetura monumental de Santiago Calatrava; corresponde a um complexo científico-cultural, resultado de intervenções urbanísticas em áreas deterioradas, com o objetivo de inserção da cidade no Terceiro Milênio. Recentemente registraram-se problemas de custobenefício, na medida em que o espaço está subutilizado.

Geo UERJ - Ano 14, nº 23 , v. 2, $2^{\circ}$ semestre de 2012 p. $459-478$

ISSN: 1415-7543 E-ISSN: 1981-9021

http://www.e-publicacoes.uerj.br/index.php/geouerj 


\section{Referências}

CACHINHO, Herculano. Mercados: extinção ou revitalização? Disponível em http://www.dn.pt/inicio/portugal/interior.aspx?content_id=1553322 Acesso em 30 abril 2012.

CAPEL, Horacio. El modelo Barcelona: un examen crítico. 1 ed. Barcelona: Serbal, 2005, 119 p.

CAPEL, Horacio. Derecho para la ciudad en una sociedad democrática: respuesta a Jean-Pierre Garnier. Disponível em www.ub.es/geocrit/sn/sn-353.htm. Acesso em 28 outubro 2012.

CARLOS, Ana Fani Alessandri. Da "organização" à "produção" do espaço no movimento do pensamento geográfico. In: CARLOS, Ana Fani Alessandri; SOUZA, Marcelo Lopes de; SPOSITO, Maria Encarnação Beltrão (Orgs). A produção do espaço urbano: agentes e processo, escala e desafios. 1 ed. São Paulo: Contexto, 2011, 234 p., p. 53-73.

CORRÊA, Roberto Lobato. O espaço urbano. 1 ed. São Paulo: Ática, 1989, 94 p.

CORREAA, Roberto Lobato. Interações espaciais. In: CASTRO, Iná Elias de; GOMES, Paulo Cesar da Costa; CORRÊA, Roberto Lobato (Orgs). Explorações geográficas. 1 ed. Rio de Janeiro: Bertrand Brasil, 1997, 367 p., p. 279-318.

CORRÊA, Roberto Lobato. Sobre agentes sociais, escala e produção do espaço: um texto para discussão. In: CARLOS, Ana Fani Alessandri; SOUZA, Marcelo Lopes de; SPOSITO, Maria Encarnação Beltrão (Orgs). A produção do espaço urbano: agentes e processo, escala e desafios. 1 ed. São Paulo: Contexto, 2011, 234 p., p. 41-51.

DUARTE, Aluizio Capdeville (Org). A área central da cidade do Rio de Janeiro. Rio de Janeiro: IBGE, 1967, p.158 p.

GARCIA GALLEGO, José Manuel; CHAMORRO, Antonio Mera; PALACIOS, María Manuela González. El atractivo de um centro comercial abierto según la opinión de los clientes y de los empresarios: aplicación al casco antiguo de Badajoz. Disponível em 
www.mercasa.es/files/multimedios/1287435526_1287163463_Art_GALLEGO.pdf Acesso em 10 abril 2012.

GASNIER, Arnaud; GUILLEMOT, Lionel. Crisis and resilience of traditional city centres in France. In: SALGUEIRO, T. B. e CACHINHO, H. (Orgs.). Retail Planning for the Resilient City: consumption and urban regeneration. 1 ed. Lisboa, CEG, 2011, 332 p., p.63-79.

GUIMARÃES, Pedro, MATOS, Filipe; SALGUEIRO, Teresa Barata. Os comerciantes como actores da resiliência das áreas comerciais. In: SALGUEIRO, Teresa Barata; CACHINHO, Herculano. (Orgs). Retail planning for the resilient city: consumption and urban regeneration. 1 ed. Lisboa: CEG, 2011, 332 p., p. 105-124.

HARVEY, David. A produção capitalista do espaço. 1 ed. São Paulo: Annablume, 2005, 252 p.

JACOBS, Jane. Morte e vida de grandes cidades. 1 ed. brasileira. São Paulo: Martins Fontes, 2000, 510 p.

KÄRRHOLM, Mattias; NYLUND, Katarina; PRIETO, Paulina de la Fuente. Retail resilience in a Swedish urban landscape: An investigation of three diferents kinds of retail places. In: SALGUEIRO, Teresa Barata; CACHINHO, Herculano. (Orgs). Retail planning for the resilient city: consumption and urban regeneration. 1 ed. Lisboa: CEG, 2011, 332 p., p. 45-62.

LEFEBVRE, Henri. Espacio y política: el derecho a la ciudad II. 1 ed. Barcelona: Península, 1976, 159 p.

MONTENEGRO, Maywa. Katrina and New Orleans - Urban resilience. Disponível em http://seedmagazine.com/content/article/urban_resilience/. Acesso em 12 abril 2012.

PACHECO, Susana Mara Miranda. Terciarização e reestruturação urbana no Rio de Janeiro. Boletim GETER, ano 1, n. 1, p.1-3, fev. 1998.

PACHECO, Susana Mara Miranda. Contrapontos da reestruturação urbana no centro do Rio de Janeiro. Boletim GETER, Rio de Janeiro, ano 2, n.3, p. 1-3, nov. 1999. 
PACHECO, Susana Mara Miranda. Comércio de rua e shopping center no bairro do Leblon: um contraponto a favor da resiliência e da sustentabilidade. In: SALGUEIRO, Teresa Barata; CACHINHO, Herculano (Orgs). 1 ed. Retail planning for the resilient city: consumption and urban regeneration. Lisboa: CEG, 2011, 332 p., p.125-139.

PINTAUDI, Silvana Maria. Anotações sobre o espaço do comércio e do consumo. In: CARRERAS, Carles; PACHECO, Susana Mara Miranda (Orgs). Cidade e comércio: a rua comercial na perspectiva internacional. 1 ed. Rio de Janeiro: Armazém das Letras, 2009, 284 p., p. 55-61.

RIPOL, Javier Casares. El comercio en la literatura: vender y escribir. Disponível em http://www.mercasa.es/publicacion/distribucion_y_consumo_-_n_50. Acesso em 15 abril 2012.

ROJAS MARCOS, Luis. Superar la adversidad: el poder de la resiliencia. 1 ed. Madrid: Espasa, 2011, 255 p.

SALGUEIRO, Teresa Barata. The resilience or urban retail areas. In: SALGUEIRO, Teresa Barata e CACHINHO, Herculano. (Orgs). Retail planning for the resilient city: consumption and urban regeneration. 1 ed. Lisboa: CEG, 2011, 332 p., p. 19-44.

SANTOS, Milton. Metamorfoses do espaço habitado. 3 ed. São Paulo: Hucitec, 1994a, $124 \mathrm{p}$.

SANTOS, Milton. Por uma economia política da cidade. 1 ed. São Paulo: Hucitec, 1994b, 145 p.

SANTOS, Milton. O Espaço dividido. 2 ed. São Paulo: Edusp: 2004, 440 p.

SPOSITO, Maria Encarnação Beltrão. A produção do espaço urbano: escalas, diferenças e desigualdades socioespaciais. In: CARLOS, Ana Fani Alessandri; SOUZA, Marcelo Lopes de; SPOSITO, Maria Encarnação Beltrão (Orgs). A produção do espaço urbano: agentes e processo, escala e desafios. 1 ed. São Paulo: Contexto, 2011, 234 p., p. 123-145. 
Artigo encaminhado para publicação em novembro de 2012.

Artigo aceito para publicação em novembro de 2012.

Geo UERJ - Ano 14, nº ${ }^{\circ}$ 23, v. 2, $2^{\circ}$ semestre de 2012 p. $459-478$

ISSN: 1415-7543 E-ISSN: 1981-9021

http://www.e-publicacoes.uerj.br/index.php/geouerj 